\title{
The characteristics of landslide with accumulation layer-bedrock contact surface -taking Langao county in China as an example
}

\author{
Peng LI 1,2,a, Shengrui SU ${ }^{1, b}$, Chi MA ${ }^{1,3, c}$, Yang DONG ${ }^{1, d}$ \\ ${ }^{1}$ College of Geology Engineering and Geomatic, Chang'an University, Xi'an, China, 710054 \\ ${ }^{2}$ Open Research Laboratory of Geotechnical Engineering, The Ministry of Land Resources, Xi'an, \\ China, 710054 \\ ${ }^{3}$ China coal xi 'an design engineering co., LTD., Xi'an, China, 710054 \\ alipeng198782@163.com, bshegnruisu@163.com, c826622963@qq.com, d1376135801@qq.com
}

Key words: Accumulation layer-bedrock contact surface; landslide; weak structural surface; Langao county; characteristics

Abstract: Taking landslide with accumulation layer-bedrock contact surface which located in Langao county in Shaanxi province as the research object, the basic characters of landslides are summarized by field investigating, engineering geological analyzing and mathematical statistics method, the main characters can be concluded as follows:(1)those landslides mainly distribute in $600 \mathrm{~m} \sim 1200 \mathrm{~m}$ elevation, slope forms are mainly convex with 180 $270{ }^{\circ}$ dips and 20 40 ${ }^{\circ}$ gradient, meanwhile, those landslides distribute along the tectonic zone; (2) this kind of landslide is always shallow landslide, their property are mainly composed by crushed silty clay or gravel soil, The sliding form is mainly arc and line, which is easy to form "debris flow" during the sliding process;(3) the main failure mode are creep-rupture and slip-push. This research has guiding significance to reveal the formation mechanism and disaster prevention of landslide with accumulation layer-bedrock contact surface.

\section{Introduction}

As its complex natural geological conditions, China subjects to a large number of geological disaster, according to Statistical data, from 2005 to 2014, there are nearly 270,305 geological disasters occurred in China, almost $73 \%$ of them are landslides ${ }^{[1]}$,causing 8014 people to disappear, 3805 people were injured, meanwhile, it caused 46.761 billion RMB economic losses. The slopes are extensively contain structural surface, mainly in the form of layers, weak layers, accumulation layer-bedrock contact surface and soon on ${ }^{[2,3]}$, the accumulation layer-bedrock contact surface is characterized by discontinuities and low intensity interfaces, most slope instability is controlled by this structural surface ${ }^{[4-7]}$.

As a kind of accumulation landslide, the deformation law, influencing factors and forming mechanism of the accumulation layer-bedrock contact landslide have been studied accordingly. Compared with the monitoring value, Yang found that the shape of bedrock surface has great influence on the stability and resurrection of the landslide ${ }^{[8]}$. Wu has concluded that the material structure of the landslide is loose, it provides a convenient channel for the infiltration of rainwater, which reduces the mechanical properties of the sliding soil and the dynamic tension along the slope , resulting in its sliding ${ }^{[9]}$. Chen reveals that the rainfall and groundwater level change is the main reason for most of the accumulation landslides ${ }^{[10]}$. Tang reveals the correlation between rainfall and landslide from microcosm ${ }^{[11]}$. Luo concludes that the soil-rock interface can control the formation of resurrection of the landslide ${ }^{[12]}$. Zhu found that the accumulation layer-bedrock contact 
landslides mainly occur in the limestone, shale and clay, Slate and clay rock surface ${ }^{[3,6]}$. Jiang and $\mathrm{Li}$ found that the groundwater is also the main natural factor affecting the slope stability. The soil-rock interface provides a good channel for water migrating, finally lead to the emergence of landslides ${ }^{[13]}$.

However, up to now, no scholars have specifically summed up the characteristics of the accumulation layer-bedrock contact surface landslide, which seriously restricted the mechanism of landslide formation revealing and disaster prevention. This paper summarizes the characteristics of this type of landslide, and analyzes its formation mechanism and influencing factors in the Langao County, Shaanxi Province, and provide significant guiding to disaster prevention and mitigation.

\section{Research background}

Langao County is located in the tectonic unit contact zone between Qinling and the Yangtze platform with lots of folds and faults, the main topography of the research area is mountains in north and valley in south. The stratigraphy of the study area is mainly composed of medium-thick layer of hard carbonate rocks, flaky soft metamorphic rocks, massive hard magmatic rocks and cohesive soils and gravel soils, of which the Quaternary system Gravel clay soil demonstrates loose and low strength. Because of abundant rainfall, human engineering activities and geological structure, there are great number of geological disasters development. The county has 502 geological disasters, of which 440 are landslides ${ }^{[14]}$.

\section{Landslide Characteristics}

\section{Geological environment characteristics}

\section{Topography}

Slope form is a key factor to slope stability, with internal and external geological forces changes, the slope height, slope gradient and shape are changing, meanwhile, slope stability also changes

(1) Slope gradient

Slope gradient affects the distribution of accumulation layer, thickness and stress states directly ${ }^{[15]}$. According to statistical result, The slope gradient of landslide in the study area is $20^{\circ} \sim$ $40^{\circ}$, accounting for $82.7 \%$ of the total landslide. It could be concluded that the gradient changes little before and after sliding, which controlled by underlying bedrock surface (Fig. 1).

(2) Aspect

Due to the influence of river and other factors, the landslide in the study area has occurred in different aspect ${ }^{[16]}$, but mainly developed in $180^{\circ} \sim 270^{\circ}$ (Fig. 2). The aspect leads to the weathered degree various, water content, permeability and the deformation at the interface are different. These factors have an important influence on the development of this kind of landslide. The probability of landslide is greater than that of shady slope.

\section{(3) Slope form}

The landslide in the study area is divided into four types: straight, concave, convex and stepped. Among them, the convex shape take up the highest proportion of $32 \%$, followed by the concave (25\%), step (23\%), straight (20\%) (Fig. 3).

\section{Geological structure characteristics}

The geologic structure has a greater impact on the development of the landslide, and the landslide will be linearly distributed along the recently active fault zone ${ }^{[17]}$. This rule also exists for the accumulation layer-bedrock contact surface landslide, but in the south, There are few landslides distribution, which is related to the population density and the geological condition. 


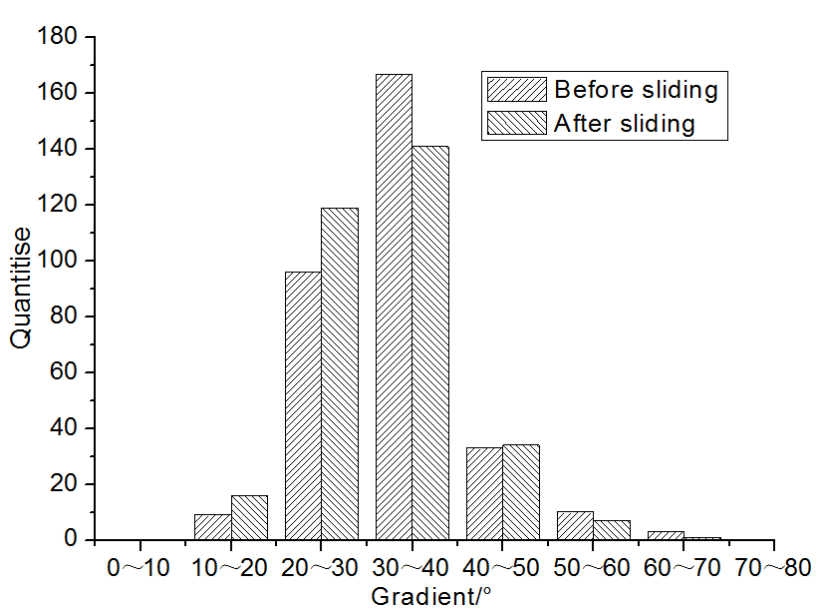

Fig.1 Slope angles before and after sliding

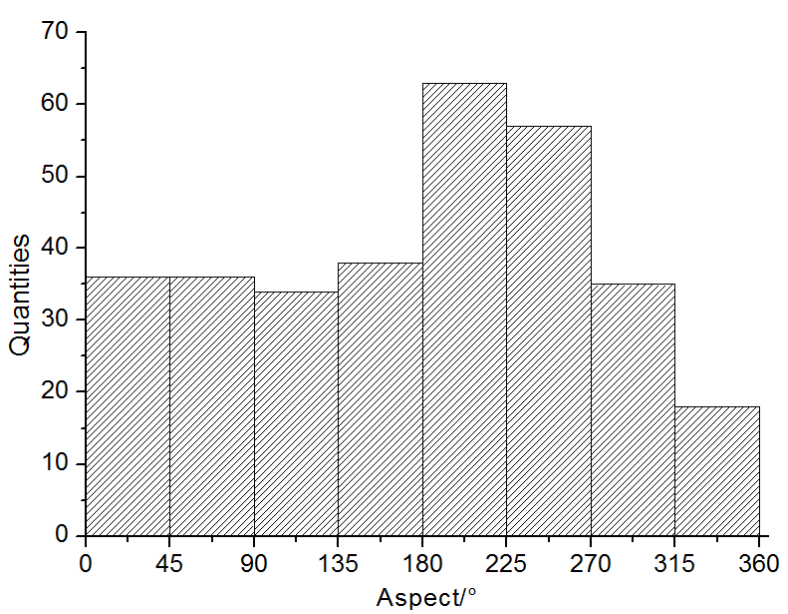

Fig. 2 Slope aspect law Lithology characteristics

Slope's rock and soil is the key element to determine the stability ${ }^{[18,19]}$. The lithology, structure type and soft and hard degree of rock and soil have the influence on mechanical properties and weathering resistance, which gradually affect the stability of slope. According to the form of underlying bedrock, the landslide in the study area is divided into five different structural types. As shown in Fig. 4, when the underlying bedrock is a fractured structure, the landslide proportion is highest, which is due to the fractured rock mass is easy to form a thicker accumulation layer, the underlying bedrock joints fissure development, easier to form a weak structural surface.

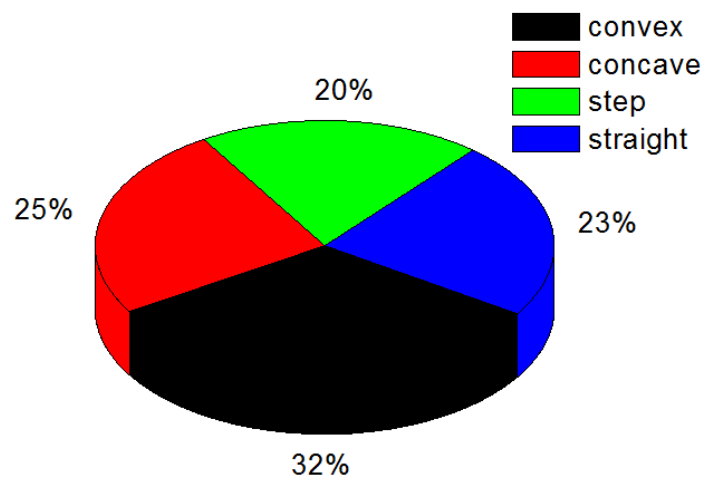

Fig. 3 Distribution ratio in different forms



Fig. 4 Distribution ratio in different structure

\section{Material composition and structural characteristics}

Material composition characteristics

Landslides with accumulation layer-bedrock contact surface are generally composed by gravel soil and crushed silty clay, those soil contain some characteristics, that is, scattered structural, large pores and strong water permeability. Base on gravel content $(s)$ and its size $(r)$, landslides ratio can be calculated. As shown in Fig. 5, almost all landslides' particle size is less than $10 \mathrm{~cm}$, and the accounts for $68.55 \%$ of the total landslide with maximum particle size is less than $5 \mathrm{~cm}$. As shown in Fig. 6, The gravel content is concentrated in $10 \% \sim 70 \%$, accounted for $54.52 \%$ of the total landslide with gravel content take up $10 \% \sim 25 \%$. The physical and mechanical properties of the soil are determined by the soil and stone together $\mathrm{s}^{[20]}$.

Slope structure characteristics

Based on the investigation and analysis of the 318 accumulation layer-bedrock contact landslides in Langao County, it is found that the landslide has the following characteristics in the structure. 


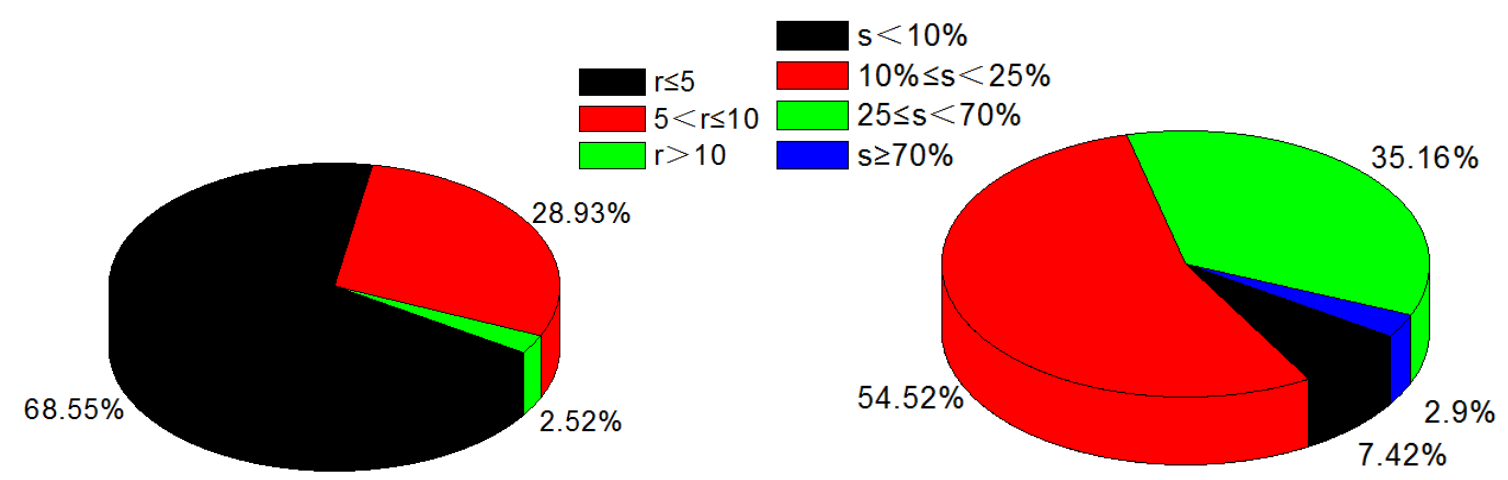

Fig. 5 Distribution ratio based on gravel sizes Fig. 6 Distribution ratio based on gravel content (1) Sliding surface characteristics

The slip surfaces are mainly the contact surface between the accumulation layer and the bedrock. The sliding surface can be divided into arc shape, linear shape, step shape and undulating shape. The ratio of deep and slip type is shown in Fig. 7 and Fig. 8. It can be seen from the figure that the buried depth of the rock mass in the Langao County is less than $12 \mathrm{~m}$, accounting for $90.3 \%$ of the total landslides, and most of them are concentrated between $2 \sim 4 \mathrm{~m}$. The results show that the arc and the line are main forms, and the slip surface is mainly controlled by the shape of the bedrock.
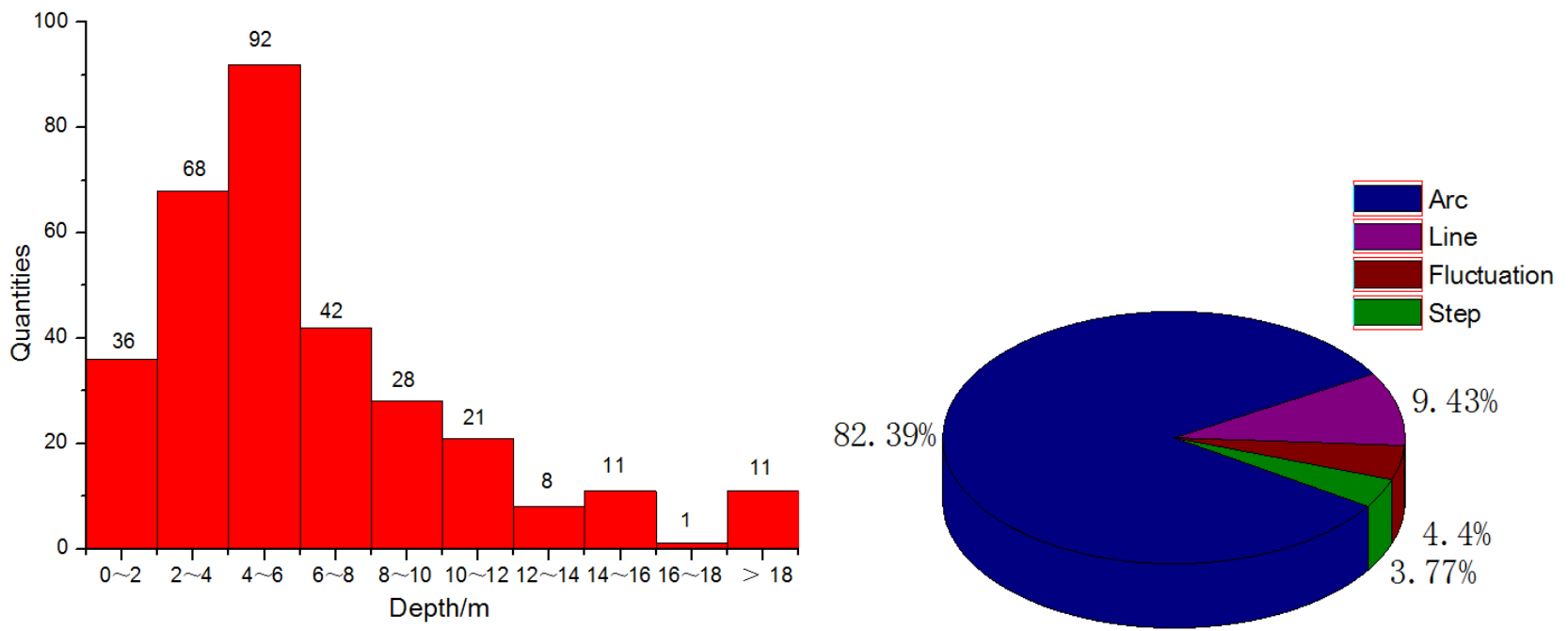

Fig. 7 The burial depth of sliding surface Fig. 8 The proportion of sliding surface in different types

(2) Fissure characteristics

There are three types of fissures in this kind of landslide: the soil dry fissure, the separation fissure and the shear fissure. The surface soil of Langao County is mostly cohesive soil. Under the dry condition, the permeability coefficient of the cohesive soil is much larger than that of the normal state due to the dry fissure existing ${ }^{[21]}$, The existence of these fissures not only increases the voids in the soil, But also lead to the increase of soil permeability coefficient, indirectly affect the water content of soil, which has an impact on slope stability. There are always appear separation fissure in trailing edge and front section of the slope, and it is easy to produce shear fissures near the boundary of both sides of the landslide with slope sliding.

(3) "Debris flow" characteristics

In the process of slip, due to the complex materials, relatively loose structural, steep slope gradient, the slope disintegrate easily with slipping, then transform into "Debris flow". This kind of "debris flow" slip surface is usually shallow, belonging to the surface damage.

\section{Landslide failure mode}

Based on the summary of the landslide failure model in the study area, the two typical failure 
modes, namely creep - rupture and slip - push mode.

(1) Creep - rupture failure mode

This model is widely distributed in the Langao County. Due to rainfall, house construction, slope farmland irrigation and other reasons, the surface of the slope creep. Afterwards, the trailing edge produces tensile stress and fissures. Under the rainfall condition, the rainwater infiltration increases the creep deformation of the slope body, and the rear edge gradually appears with wide fissures and even the anti-slope step, and the shear stress concentration near the potential slip surface occurs. With the deformation intensified, the middle of the slope occur expansion. Through the survey found that most of this kind of landslide does not appear intense slip in a long time, while always in the position of creep deformation stage, which is easy to make the villagers paralyzed, causing greater harm. The evolution process of this mode is usually divided into four stages: creep, slip, intense slip and stability.

(2) Slip - Push the failure mode

This kind of failure mode often occurs in the slope with steep structural plane. Due to rain, blasting, vibration, slope foot excavation and other factors, it is easy to slide suddenly. This type of landslide usually occurs short duration, small scale, fast sliding speed, creep stage is short, if there is a residential housing or road, it is likely to cause a greater loss. The evolution process is divided into three stages: un-slip stage, intense slip stage, stable stage.

\section{Conclusions}

Based on the research results of accumulation lay-bedrock contact surface landslide, this paper systematically studied the basic geological and environmental characteristic, material composition and structural, deformation and failure characteristics in combination with the survey data of landslide in Langao County, Shaanxi Province. the conclusions are as follows:

(1)The landslide in the study area is mainly developed in the convex slope with $600 \mathrm{~m} \sim 1200 \mathrm{~m}$ elevation, $20 \sim 40{ }^{\circ}$ slope gradient and $180 \sim 270{ }^{\circ}$ dips, and its sedimentary structure is striped. When the bedrock is a fractured structure, such landslides are particularly developed.

(2)The composition of the landslide material is mainly crushed silty clay or gravel soil, the maximum particle size of gravel is less than $5 \mathrm{~cm}$, and the gravel content in the slippery body is concentrated in $10 \% \sim 25 \%$.

(3)The landslides of this type are mostly superficial landslides. The sliding form is dominated by arc and line, which is easy to form "debris flow" during the sliding process.

(4) The failure modes of this types landslides are creep-rupture and slip - push.

\section{Acknowledgements}

This work was financially supported by the Fundamental Research Funds for the Central Universities (310826151048)

\section{References}

[1] Information on http://www.cgs.gov.cn/index.htm.

[2] Y. G. Journal of Geological Hazards and Environmental Protection. Vol. 14, No. 4(2003),p. 1-5.

[3] J.P. Jiang, G. Y. Luo. Journal of Engineering Geology. No. 4(2000),p.438-441.

[4] Y. Y. Yang. Joints rock mass damage fracture mechanics model and its application in rock mass engineering field (Tsinghua University ,Beijing 1990).

[5] E. Hoek. Rock Engineering (Evert Hoek Consulting Engineering Inc, North Vancouver 2000). 
[6] D. P. Zhu. Revial mechanism and deformation prediction of typical accumulative landslide in the three gorges(China University of Geosciences, Wuhan 2010).

[7] H. He. Research on micropile reinforcing mechanism and application of expansive soil landslide in shallow accumulative layer (Xi 'an University of Science and Technology ,Xi 'an 2013).

[8] J. B. Yang. Journal of Disaster Science. No.2(1995),p. 38-42.

[9] H. Z. Wu, M. G. Feng, Y. Y. Jiao, et al. Rock and Soil Mechanics. No. S1( 2010). P, 324-329.

[10] S. X. Chen, X. C. Xu, H. B. Xu. Rock and Soil Mechanics. No. S2(2005), p. 6-10.

[11] L. S. Tang, C. Y. Zhou. Acta Scientiarum Naturalium Universitatis Sunyatseni, No.6(1996), p. 96-101.

[12] G. Y. Luo, P.Q. Wang, H. Wu, et al. Hunan Hydro, No.1 (1981 ), p. 12-16.

[13] J.P. Jiang, X. Z. Li, G.Y. Luo. Advance in Water Science, No.1(2007), P. 34-38.

[14] N.B. Zhang. The evaluating of the susceptibility about geological disaster in Langao County based on GIS(Chang'an University ,Xi'an 2012).

[15] Z. C. Kang, Z. F. Li, A. N. Ma: Debris flow research in China(Science Press, Beijing, 2004).

[16] H. Zhang. Study on characteristics and formation mechanism of Langao geological hazards(Chang'an University, Xi'an 2012).

[17] Z. Y. Zhang, S. T. Wang, L. S. Wang, et al: Engineering geology analysis (Geological Publishing House, Beijing, 2009).

[18] H.M. Tang: Engineering geology(Chemical Industry Press, Beijing ,2008).

[19] J. Zhang. Study on the unload-load responseration of debris landslide and its stability evolution-selecting Bazimen landslide as the example(University of Science and Technology, Qingdao 2011).

[20] X. H. You, G. He, X. Li. Hydrogeology and Engineering Geology, Vol. 30, No. 1(2003),p. $18-21$.

[21] J. S. Hanor. Water Resources Research, Vol. 29, No. 11(1993), p. 3691-3698.

[22] W. M. Yang. Three gorges - qinba area typical landslide formation mechanism and evolution research(Chinese Academy of Geological Sciences, Beijing 2006). 